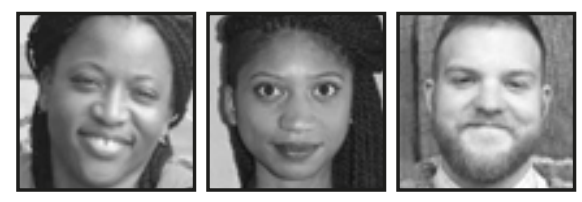

\title{
Creating Spaces for Arts-Informed Responses in Teacher Education Programs
}

\author{
Lerona Dana Lewis, Asia Wright-Harvey, and Tobias Moisey, \\ McGill University
}

\begin{abstract}
We address the benefits and challenges of using an arts-informed response in an undergraduate teacher education course from the perspective of a teacher and two students. Feminist pedagogies provide the theoretical lens through which our experiences are analyzed. From the teacher's perspective, this arts-informed approach modeled to pre-service teachers how they could use arts-informed inquiry in their future classrooms, to engage in conscious raising about inequality, while meeting different learning styles in their classrooms. From the students' perspective, it was surprising to be invited to do an arts-informed reading response. Acceptance depended on the perception of risk. Our conclusion is that more space should be created for arts-informed approaches in undergraduate teacher education programs.
\end{abstract}

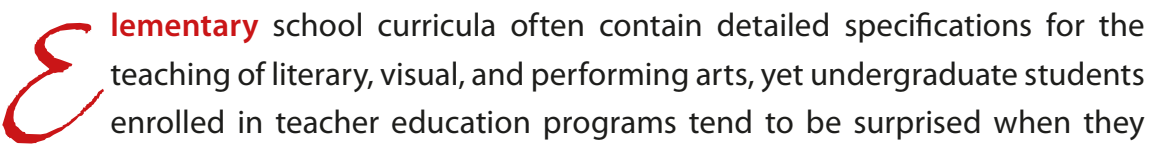
are asked to engage in arts-informed inquiry in their course work. We posit that preservice teachers can benefit from teaching strategies that illustrate and model how to incorporate the arts across the curriculum. Our paper explores the incorporation of an arts-informed reading response in an undergraduate course designed to teach pre-service teachers about global education and social justice. We highlight what the arts helped the teacher and students to "see" differently, as well as the reasons why (even if students are trained in visual or performing arts), they may still choose to do the 
traditional essay-type response to a reading. We conclude with a critical discussion on the arts and accessibility, and offer suggestions for research and teaching.

The benefit that the arts bring to teaching and learning in the school curriculum is well documented. Incorporating literary, visual, and performing arts in the school curriculum is thought to be beneficial to students, improving their mental health, self-confidence, creativity, and problem-solving skills. Art in the curriculum encourages risk taking because students use their creativity. Moreover, it encourages diversity and promotes multiculturalism in schools (Roege \& Kim, 2013). Among the implications for the teaching profession, Gulatt (2008) argues that the arts promote the role of teachers as facilitators of learning, and not dispensers of knowledge. Integrating arts into the curriculum uses knowledge in authentic ways, instead of simply reproducing knowledge (Rabkin \& Redmond, 2006). Maxine Greene argued that the arts allow for conscious awakening and questioning of taken-for-granted myths. Thus, when the arts inform the school curriculum, teaching and learning can, in the words of Paulo Freire (2005), "provoke learner consciousness" to challenge the status quo and imagine a different world.

Efland (1990) explained that historically, access to arts instruction was shaped by social class and gender. For instance, working-class women could study decorative arts, while fine arts instruction was reserved for men. Today, teaching of literary, performing, and visual arts is one of the focal points of elementary and high school curricula. In elementary schools there is the expectation, based on the curricula, that students will have the opportunity to engage in cross-curricular integrated learning. This is stipulated in both the Ontario curriculum and the Quebec Education Program. The curriculum is expected to provide students with integrated learning opportunities where they draw on the arts to gain or present insights into their other subject areas. The Ontario curriculum promotes "learning through the arts," and states,

Various aspects of the arts can also be used to illuminate other aspects of the school curriculum or to help develop students' skills in other subjects. For example, teachers may have students demonstrate their learning in other subjects by using artistic modes of expression. Through integration of the arts with other subjects, students can also develop broader abilities - for example, communication skills. (Ontario Ministry of Education, The Ontario Curriculum, Grades 1-8, The Arts, p. 6)

The Quebec Education Program dedicates a section that specifies the ways that crosscurricular competencies should be developed in the schools. All teachers are expected to help students to develop their artistic skills by incorporating the arts in their specific subject areas. 
The emphasis on integrating or infusing the arts across the curriculum generally occurs before tertiary level schooling. However, there appears to be burgeoning interest in the idea of integrating arts into the curriculum in higher education. Van der Veen (2012) provided an example of incorporating arts in college physics to reduce barriers to the language of physics. He suggested that having college students draw their understanding of a journal article or concept in physics was a powerful way of assessing students' prior knowledge and attitudes toward science. Izmirli and Baird (2002) provided a model for integrating arts and technology in college. They reported that the combination gave students greater appreciation for the aesthetics in computer science projects, and made computer science more attractive to the students who perceived themselves to be artistic. Although these authors did not locate their work with the movement advocating arts in Science, Technology, Engineering ARTs and Math, (STEAM), the goal of STEAM applies to their approaches. The goal of incorporating the arts into science is to foster and enhance creativity as well as the risk taking needed to advance the application of science to solve problems innovatively (Root-Bernstein, 2008).

In the field of teacher education, arts-based inquiry is used as a form of qualitative research to improve the development of teacher research (Diamond \& Mullen, 1999). Less has been written about the experience of incorporating the arts across curricula in undergraduate teacher education courses. Furthermore, existing research shows that efforts to use arts in teacher education programs were not always well received by students. Hirsch (2010) found that student teachers were resistant to the incorporation of arts in their social studies curriculum. She reported that the students felt it was a "waste of time, demeaning and silly" (p. 323). Our paper is located within the field of inquiry of using arts in teaching in higher education, but outside traditional literary, visual, and performing arts classes. We aim to explore the benefits and challenges associated with incorporating the arts into university curriculum in a course designed to teach about social justice. Our work contributes to the scholarship on incorporating the arts across teacher education programs. The paper presents the perspectives of a teacher and two students (a vocalist and a musician).

\section{Teacher's Perspectives on Arts-Informed Approaches}

I (Lerona) had taken a graduate course in arts-informed inquiry and I had come to appreciate the benefits of the arts in research. For instance, I explored found poetry as a research tool. Found poetry is poetry that is created when words in narratives, 
popular texts, or even existing poetry are transformed to the poetic form by altering for example, the spacing, and line breaks. The resulting poem can represent what would otherwise go unnoticed (Butler-Kisber, 2002, 2010). During this graduate course, I also explored collages, photovoice, readers' theatre, and other forms of arts-based inquiry. I had come to understand what Maxine Greene (2001) meant when she talked about the meanings that may be released because of an encounter with art, and that the arts are "modes of sense-making" (p. 41). For example, Greene explained that poetry is created by writers who are moved to make metaphors after exploring the phenomenological world and selecting the parts that have potential meaning to them.

My experience with the arts began before university. From childhood to early adulthood, I was dancer trained in modern and folk dance. As a choreographer and performer, I knew intimately that dance could be used to tell stories from multiple perspectives. My prior experience as a performer and my work with artsinformed research gave me the impetus to integrate arts-informed approaches in undergraduate teaching. The response from students was generally negative in the first course in which I introduced an arts-informed project. In their anonymous online evaluations, students expressed the view that the arts-informed project was "silly" and that they simply "made up things." I did not abandon the idea of arts-informed coursework. Instead, I reduced the percentage of their final grade allocated to the artsinformed assignments. I no longer assigned arts-informed projects as a mandatory component of coursework.

\section{Course Description and Assignment}

The course that we discuss is part of a bachelor of education degree, but it can be taken as an elective by students outside the Faculty of Education in a university in eastern Canada. The title of the course is "Global Education and Social Justice." One of the objectives of the course is to have students question the ways that they may be complicit in perpetuating injustice and oppression through their consumption habits (food, clothing, and recreation, as in tourist visits). The students were expected to make connections between local and global patterns of injustice.

To achieve these objectives, students were expected to consider how theories of production might explain the role and possible "benefit" of capitalism in society, and how a profit motive could contribute to income inequality and wealth disparity. A Marxist perspective on capitalism was presented as one way of understanding the 
process of production and the persistent dominance of capitalist, neoliberal ideologies in global markets. Two documentary films and various readings were used to prompt discussion on these ideas.

The documentary, The Price of Sugar (Haney \& Grunebaum, 2007), exposed the contradictions of the Dominican Republic, which is a popular tourist destination for Canadians. On one hand, the island has a well-developed tourism product, and markets itself as tropical paradise. On the other hand, the film documented the violations of human rights that the Haitian farm workers endure while working on the sugar plantations in the Dominican Republic. The documentary film entitled The Toxins Return (Altemeier, 2009) traced the movement of dangerous toxins in the clothing and fashion industry through India, Hong Kong, and across Europe to fashion outlets in Germany. The film highlighted the absence of regulatory framework and the harmful effect of these chemicals on the respiratory and nervous system of German employees in the clothing merchandising industry. Indian farmers in debt who worked in cotton fields and in factories dying fabrics black developed various forms of debilitating cancers. These working conditions were contrasted with the glamorous images of stylish fashion models on the runways.

In order to begin to link global to local context, the students read Chapter 2: Context, from the text "Fight Back: Work Place Justice for Immigrants" (Choudhry, Hanley, Jordan, Shragge, \& Stiegman 2009, pp. 15-32). This chapter described and explained why newly arrived immigrants to Montreal have the highest risk of living in poverty. It also outlined the history of institutional racism in Canadian immigration policies, such as the Chinese Head Tax. Later, I assigned Chapter 5: Justice for Farm Workers (pp. 57-73) and asked students to critically respond to the reading, identifying three themes. I gave students the choice to do an arts-informed response or the traditional reading response. I told the students that their arts-informed response could be in the form of a poem, a short story, a sketch, a comic, or any other form of their choice. One of my aims was to illustrate to students how the arts could be incorporated into the classes, such as social studies or history, because this incorporation is a requirement of elementary and high school curricula. I hoped that through the creative process students would use their imagination. I view imagination as the capacity to perceive alternative realities that could stimulate empathy through the use of metaphors (Greene, 2001). I aimed for students to have what Greene referred to as an aesthetic experience through the creation of their arts-informed response and through which they may "see" something new. 
I scheduled one class period of 105 minutes for students to respond to the reading. I aimed to provide structure to the task so that it could fit within what I perceived students would feel was the expected discursive practices of a university class assignment. These practices include a time constrained, structured, partially closed-ended assignment to be completed in a classroom, with corresponding detailed assessment rubrics. The main reading and the different evaluation rubrics for both the traditional and the arts-informed responses were available prior to the date of the class assignment. However, students were not confined to responding to one reading. If students were absent with a valid reason, they were allowed to do the arts-informed response as a take-home assignment. I asked them to upload their responses to the secured university online learning platform or submit a hard copy. I built on the students' responses to plan for subsequent classes, instead of lecturing on the injustices associated with globalized production. Since students had assigned classroom time to respond to the reading, I anticipated informed critical discussions and avid participation in subsequent classes on this topic.

\section{Student Response to Arts-Informed Reading Response}

I taught the course twice and assigned the arts-informed reading both times. The number of students who opted to do the arts-informed response this time was slightly higher (1\%) than the previous year. Over the two years, on average $30 \%$ of students opted for the arts-informed response. The students' responses ranged from short stories, journal entries, satirical pieces, poems, and lyrics for songs, comics, sketches, and collages. Students' responses were emotive and captured the spirit of the struggles of the farm workers employed in the Seasonal Agricultural Workers' Program in Quebec described in the assigned reading. The racialized nature of the exploitation was noted. Several students referred to the brown or dark skin of these workers in their poems.

The first year that I taught the course, I received an email from a student who thanked me for giving him the chance to be creative and expressing how unexpected it was for him to be asked to be creative in a university course. He expressed the desire to have this opportunity in other university courses. This theme of surprise when being asked to be creative is present again as both co-authors expressed similar sentiments. 


\section{Perspective From Student Who Chose the Arts-Informed Assignment Response}

I (Tobias) was surprised to be offered an arts-informed response in a university class. From its first mention my mind started churning through ideas on how I could artistically respond to the themes of the course readings. As a musician and having studied music academically, I had many options and felt confident to experiment.

We were to respond to varied material, a text on migrant workers, and a video documentary on the clothing industry entitled, The Toxins Return. I felt that the audio component of the documentary was the perfect material to experiment with Music Concrete, an experimental technique of musical composition that uses recorded sounds, or samples, as raw material. The principle uses samples to produce an aural montage, a soundscape. While viewing the documentary I kept note of the timing of phrases, single words, and sounds that drew an emotional response. Using a free digital audio manipulating program, I cut out these phrases and words and organized them into themes-and from this I created three montages. To complete the soundscape I separated these montages with samples I created with the flute to contrast and highlight the themes of the original documentary. My response was possible because I had the skill, technology, and time to create and produce a finished work.

\section{4) Click here to listen to Tobias's art-informed audio response}

An arts-informed response is a brave way for students to emotionally respond to concepts and ideas we present as educators, however, there are limits that must be considered. Students who have little artistic experience may feel limited to create work and feel afraid to have their work assessed. As educators we can combat these feelings by modeling different forms of artistic responses to guide students in the creation of their responses. Having students collaborate supports those who feel lost in the art making and opens discussion. Educators must combat their own fears and inadequacies to find their students' diverse talents. As a musician I will learn from my visual artists, poets, videographers, and vice versa. Time must be allowed for ideas to distill into effective creations and experimentation must be valued. There are many ways to explore, to respond to content other than the traditional essay, and I challenge my colleagues to go out of their comfort zones, away from what is expected, and take risks - the results will be surprising and refreshing for them and their students. 


\section{Perspective From Student Who Did Not Choose the Arts-Informed Response}

Although I (Asia) am a music student majoring in jazz voice, when presented with the opportunity to do an arts-informed response in one of my university courses, I ultimately decided not to, opting instead to complete an in-class essay on the given material. Initially, I thought the assignment seemed like a fun and interesting alternative to the traditional essay, as incorporating creative aspects into subjects that aren't inherently artistic, and are more based in reading and critical thinking, was something I was interested in exploring. I considered putting together some sort of original song that incorporated all the themes we were to discuss, but upon further reflection the task began to seem dauntingly vague. The possibilities available for me to choose from were endless, somewhat overwhelmingly so. I began to worry that if I were to go that route I would perhaps misinterpret some aspect of the assignment, or that my symbolic presentation of themes through music wouldn't be something one could assess objectively, and my grade would suffer because of it.

Another significant factor was the massive amount of time that would need to be allocated towards creating an arts-informed response. To compose and record a song takes a significant amount of time (for me at least), a luxury I didn't have. It was a much faster and simpler process to outline the points I wanted to make at home, and write the essay in class. Yet, another contributing factor was that I had never experimented with any type of complex digital remixing before, and a graded assignment did not seem like the place for experimentation. Essays, however, are asked of students frequently, and to write one has become a routine that most university-level students are comfortable with completing and presenting for a mark. The fourth and final factor that solidified my decision to not complete an arts-informed response is that to compose a song would have been a much more vulnerable exercise, and if what I presented was not well received, it would be difficult not to take the mark personally.

Looking back, I now realize I could have done an arts-informed response to the reading. The majority of my reasons for not wanting to do an arts-informed response were routed in self-doubt, but excluding the shortage of time, there were no debilitating reasons that prevented the completion of an arts-informed response, and it would have been a very rewarding and enjoyable assignment. From a purely objective standpoint, I absolutely had the resources to complete an arts-informed response, and after seeing examples of what an arts-informed response can look like from other music students in the course, the task seemed less intimidating and more of a fun alternative. When given an opportunity at a later date to incorporate a musical perspective into a presentation, 
I began to regret not choosing to pursue the arts-informed response when I had the chance to earlier in the semester.

\section{Lessons From Our Experiences With the Arts-Informed Response}

From the perspective of the teacher, the arts-informed music piece submitted by (Tobias) was challenging especially because his expertise in music was clearly illustrated in his submission. It was also the first time over the four-year period that I taught and assigned arts-informed projects that I had received a musical submission. Was I, Lerona, capable of an "informed listening?" (Greene, 2001, p. 51) to the flute, the pitch, its rhythm, and melody? Paulo Freire's (2005) discussion on reading of a text is instructive here. In instances when a text is more challenging than anticipated, Freire says readers should not be immobilized by fear of not understanding, nor should they abandon their pursuit of comprehension (Freire, 2005). Considering this musical piece as a text, while I felt some apprehension, I focused on the interpretation of the themes which I heard and the abstract that accompanied the piece. I heard the themes related to debt, helplessness, and collusion of power. Greene suggests that the arts could be used to learn mathematics, to read, or to understand history (Greene, 2001). I aimed to encourage students to represent the meanings that they found in the reading using their artistic expertise and the task was accomplished.

My initial apprehension can be examined using the lens of feminist pedagogies. Feminist pedagogies are marked by the non-hierarchical relationships among teachers and students (Crabtree, Sapp, \& Licona, 2009). My role as the teacher is not to be an expert holder of knowledge, but a facilitator of the development and exchange of ideas. The goal of incorporating the arts across the curriculum is congruent with this tenet of non-hierarchical teaching and learning in feminist pedagogy. By incorporating the arts-informed response to the reading, I allowed students to be experts, even if it meant that the limits to my expertise and associated authority could be tested.

Feminist pedagogies are concerned with creating access for all students to be welcomed, and with bringing in voices that are marginalized in mainstream discourses. While there was a slight increase in the percentage of students choosing the artsinformed response (30-31\%), more than two-thirds of the class did not do the artsinformed response. Reflecting critically, I asked myself why I continued to dedicate time and space to art in my classroom, when the majority of the students did not 
choose the option. Was I aiming to bring marginalized practices into mainstream? The response to my question is twofold:

Firstly, I do not believe that all forms of literary, visual, and performing arts are marginalized. Access to arts education is not equally distributed throughout schools, despite the extensive descriptions and specifications in the curriculum documentation on the provincial level. Many children did not have opportunities for sustained artistic or creative development. Progress in most areas of art often requires family involvement and resources. Delissio (2014), in a blog "STEAM for Institutions of Higher Education," noted that students with formal artistic training were better at producing work that was both creative and correctly captured the scientific concepts. Could emphasis on arts-informed teaching and learning tacitly create conditions that privileged students who have had prior artistic access that allowed the mastery of their specific form of art?

Secondly, the present structure of schooling at the elementary and high school level often emphasizes testing, standards, or competencies and education productivity where "achievement is triumphed over inquiry" (Eisner, 2005, p. 207). These aspects of teaching likely impact what is valued in teacher education. Student teachers may not appreciate how the use of literary, visual, or performing arts in their undergraduate course work would help their future students "succeed," and therefore consider teaching with the arts as "silly."

Teaching approaches that draw on all students' strengths is important. Howard Gardner's well-known theory of multiple intelligence supports the view that teachers should match their method of instruction and assessment to the needs of their students. Using the arts-informed approach to reading responses is simply one tool in a teacher's tool kit, and does not negate exploration of other ways to tap into the different learning styles of the classroom. Unfortunately, as Gardner (2010) pointed out:

In younger grades arts education is relatively abundant...Children paint, draw, and model clay, and they sing participate in rhythm bands, or, less often play and instrument, dance or tell stories.... In middle school arts education declines in frequency... by high school specialist handle instruction and only a minority of students participate. (Langworth \& Gardner, 2010, p. 235)

Sufficient use is not made of the arts across the curriculum in higher education.

Both Eisner (2005) and Gardener (2010) strongly advocate that the processes involved in thinking through the arts - that of critical inquiry-are valuable for student 
satisfaction and learning. Ultimately, our hope for incorporating the arts across the curriculum is that we as educators can inspire what Eisner referred to as the vitality and emotions associated with the arts, which is transferable outside of schooling. We hope that what we teach, "students will want to pursue voluntarily after the artificial incentives so ubiquitous in our schools is long forgotten" (Eisner, 2005, p. 207). Tobias's experience serves as an example because he used his arts-informed response created for this class in a radio documentary.

\section{Arts Should Not Be a Surprise in Teacher Education Programs}

During the class discussions, students reported that they had no idea that people worked under such harsh conditions to produce items that are part of their daily life. They certainly had not associated Canada and Quebec with such inhumane working conditions that restricted workers' movements, access to unemployment insurance, and healthcare as discussed in Choudry et al. (2009). Tobias's arts-informed response, like that of many other arts-informed responses, helped me to see that I needed to refocus my class discussion on the possibility for change even within oppressive situations. Workers were being oppressed in global productions chains, and this notion was clearly depicted in their arts-informed responses. However, justice cannot be attained without hope. In subsequent lessons I discussed instances where workers, students, and ordinary citizens lobbied to make changes and fight situations of injustice. I believe that the arts-informed responses allowed me as teacher to see succinctly what the students took away from reading. The arts-informed response was useful pedagogically.

We recommend that arts-informed responses to readings and journal articles continue to be used as an option in undergraduate teacher education programs. Teacher educators may provide a range of examples to encourage students to participate and minimize the level of risk that students perceive to be associated with the arts informed-responses. Teacher educators using arts-informed teaching strategies could collaborate and develop resources to strengthen their knowledge of aesthetics in various arts disciplines. Arts-informed inquiry is widely accepted in education research. However, more detailed research on the use of arts across curricula in higher education is needed if the incorporation of the arts is to gain acceptance as a meaningful pedagogical approach to teaching and learning in undergraduate teacher education programs. Teacher educators' incorporation of the arts in teaching practice should not be a surprise. 


\section{References}

Altemeier, E. (Director). (2009). The toxins return [Documentary film]. New York: Films Media Group.

Butler-Kisber, L. (2002). Artful portrayals in qualitative inquiry: The road to found poetry and beyond. The Alberta Journal of Educational Research, 48(3), 229-239.

Butler-Kisber, L. (2010). Qualitative inquiry: Thematic, narrative and arts-informed perspectives. Thousand Oaks, CA: Sage Publications.

Choudy, A. Hanley, J. Jordan. S. Shragge, \& Stiegman, M. (2009). Fight back: Work place justice for immigrants. Blacks Point, NS: Fernwood.

Crabtree, R., Sapp, D., \& Licona, A. (Eds). (2009). Feminist pedagogy: Looking back to move forward. New York: John Hopkins Press.

Delissio, L. (2015). STEM (Science, Technology, Engineering, and Math) + the Art/Design = STEAM [Web log post] Retrieved from https://stemtosteamihe.wordpress.com/

Diamond, C. T. P., \& Mullen, C. A. (Eds.). (1999). The postmodern educator: Arts-based inquiries and teacher development. New York: Peter Lang

Efland, A. (1990). A history of art education: Intellectual and social currents in teaching the visual arts. New York: Teachers College Press.

Eisner, E. (2005). Reimagining schools: The selected works of Elliot W. Eisner. London: Routledge.

Freire, P. (2005). Teachers as cultural workers: Letters to those who dare to teach. Expanded edition. Translated by Macedo, D., Koike, \& Alexandre, O. Colorado: Westview Press.

Gardner, H. (2010). Multiple intelligences: New horizons in theory and practice. New York: BasicBooks.

Greene, M. (2001). Variations on a blue guitar: The Lincoln Center Institute lectures on aesthetic education. New York: Teachers College.
Gullatt, D. E. (2008). Enhancing student learning through arts integration: Implications for the profession. The High School Journal, 91(4), $12-25$.

Haney, B. (Producer/Director), \& Grunebaum, E. (Producer). (2007). The price of sugar [Documentary film]. Massachusetts: Uncommon Productions.

Hirsch, M. (2010). Embracing resistance and asymmetry in pre-service teacher aesthetic education. Arts and Humanities in Higher Education, 9(3), 322-338. doi:10.1177/1474022210379208

Izmirli, O., \& B. Baird (2002). A model for integrating arts and technology in a liberal arts college. Journal of Computing Sciences in Colleges, 17(6), 102-109.

Langworth, R., \& Gardner, H. (2010). Multiple intelligences: New horizons in theory and practice. New York: BasicBooks.

Rabkin, N., \& Redmond, R. (2006). The arts make a difference. The Journal of Arts Management, Law, and Society, 36(1), 25-32.

Ontario Ministry of Education. (2016). The Ontario Curriculum Grades 1-8 The ARTS 2009 Revised. Retrieved from http://www.edu. gov.on.ca/eng/curriculum/elementary/arts 18b09curr.pdf

Roege, G. B., \& Kim, K. H. (2013). Why we need arts education. Empirical Studies of the Arts, 31(2), 121-130. doi:10.2190/em.31.2.eov.1

Root-Bernstein, R., Allen, L., Beach, L., Bhadula, R., Fast, J., Hosey, C., et al. (2008). Arts foster scientific success: Comparison of Nobel prizewinners, Royal Society, National Academy, and Sigma Xi members. Journal of the Psychology of Science and Technology, $1(2), 51-63$.

van der Veen, J. (2012). Draw your physics homework? Art as a path to understanding in physics teaching. American Educational Research Journal, 49(2), 356-407. doi:10.3102/0002831211435521 


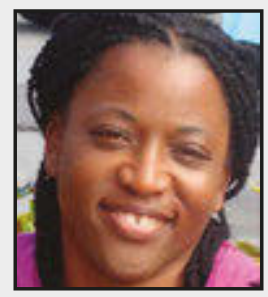

Lerona Dana Lewis is interested in issues of equity, access, and resilience in education. She completed her PhD in Educational Studies at McGill University. Her work includes research on parental involvement in education in contexts of immigration, and teaching of elementary science education. She uses both quantitative and qualitative research methods, but focuses arts-informed research methodologies. She is currently a postdoctoral fellow at the Centre for Medical Education at McGill University where she researches Culture in Faculty Development and Professional Identity in Teaching Faculty in the health professions.

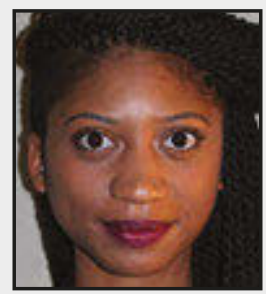

Asia Harvey-Wright, originally from Brooklyn, New York, is a music student at McGill University, studying music education. Prior to pursuing her studies up north, she attended the Professional Performing Arts School in midtown Manhattan, and majored in Musical Theater. Additionally, she spent 10 years as an active member of the Brooklyn Youth Chorus, a pre-professional vocal music ensemble with whom she was able to perform at prestigious venues all across New York City. In the hopes of sharing her love of music with generations yet to come, Asia plans on going on to teach music at the elementary school level.

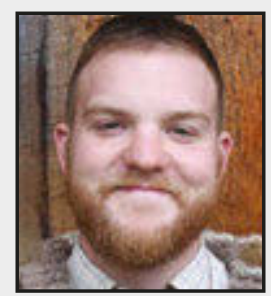

Tobias Moisey holds an MMus from the Rimsky-Korsakov Saint Petersburg State Conservatory, Russia, in Flute Performance, and a BMus from the University of Victoria, Canada, with a specialization in Music Education. Tobias is currently studying at the McGill Faculty of Education. As an active board member of the Bulkley Valley Concert Association, which presents concerts in Rural Northern British Columbia, and a representative of the Music Education Undergraduate Student Association of McGill, Tobias's interest in education brings together music performances with community development and identity exploration. Tobias is the host of CICK Smithers Community Radio's popular art music program, Culture Shock. 